\begin{tabular}{|c|c|c|}
\hline 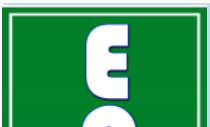 & $\begin{array}{l}\text { International Journal of Current Research in } \\
\text { Biosciences and Plant Biology }\end{array}$ & $\underline{y-5}$ \\
\hline & Volume 5 • Number 2 (February-2018) • ISSN: 2349-8080 (Online) & \\
\hline $\begin{array}{l}\text { EXCELLENT } \\
\text { PUBLISHERS }\end{array}$ & Journal homepage: www.ijcrbp.com & \\
\hline
\end{tabular}

Original Research Article

doi: https://doi.org/10.20546/ijcrbp.2018.502.004

\title{
Moisture Adsorption Isotherms Characteristic of Coffee (Arabusta) Powder at Various Fitting Models
}

\section{Yué Bi Yao Clément ${ }^{1 *}$, Yao N'zué Benjamin², Konan Brou Roger', Akmel Djédjro Clément ${ }^{3}$ and Tano Kablan ${ }^{1}$}

${ }^{1}$ Department of Food Science and Technology, Nangui Abrogoua University, 02 BP 801 Abidjan 02, Côte d'Ivoire

2Department of Agroforestery, University Jean Lorougnon Guede, BP 150 Daloa, Côte d'Ivoire

3National Polytechnic Institute Houphouet -Boigny, BP 1093 Yamoussoukro, Côte d'Ivoire

${ }^{*}$ Corresponding author.

\begin{tabular}{|c|c|}
\hline Article Info & ABSTRACT \\
\hline $\begin{array}{l}\text { Date of Acceptance: } \\
20 \text { January } 2018\end{array}$ & \multirow{4}{*}{$\begin{array}{l}\text { Water sorption test of coffee (Arabusta) powder carried out under laboratory conditions } \\
\text { are presented together with mathematical analyses of the moisture adsorption } \\
\text { isotherms. Coffee powder moisture adsorption isotherms were determined within the } \\
\text { range of } 0.07-0.97 \text { water activity at } 29^{\circ} \mathrm{C} \text {, using saturated salt solutions dynamic } \\
\text { method. Sorption isotherms of coffee powder have a sigmoid sharp (type II). The data } \\
\text { obtained were fitted to several models of two-parameter (BET, Hasleys, Kuhn, Chung } \\
\text { and Pfost, Freundlich and Oswin) and three-parameter (GAB). A non-linear least } \\
\text { square regression analysis was used to evaluate the models constants.In relation to the } \\
\text { isotherm models the best models were Halsey (in the wide range of water activity) and } \\
\text { Kuhn (in the range of water activity } 0.07-0.5 \text { ) obtaining minor values of } \% \text { mean } \\
\text { relative errors and higher correlation coefficient. Critical value of equilibrium moisture } \\
\text { content of coffee powder corresponding to the aw equal to } 0.6 \text { was } 34.6 \text { g water per } 100 \\
\text { g dry matter. These values are useful for storing conditions optimisation from the point } \\
\text { of view of microorganisms growth and structural changes analyses. The monolayer } \\
\text { moisture content values for BET were higher than those for GAB, these values are } 22.14 \\
\text { and } 2.57 \mathrm{~g} \text { water per } 100 \mathrm{~g} \text { dry matter, respectively. }\end{array}$} \\
\hline $\begin{array}{l}\text { Date of Publication: } \\
\text { 06 February } 2018\end{array}$ & \\
\hline Keywords & \\
\hline $\begin{array}{l}\text { Coffee powder } \\
\text { Equilibrium moisture content } \\
\text { Modelling } \\
\text { Moisture adsorption isotherm }\end{array}$ & \\
\hline
\end{tabular}

\section{Introduction}

Coffee is considered one of the most important products in Côte d'Ivoire, because of the income from exportation and industrialisation and the number of direct and indirect employments related to this commodity. Côte d'Ivoire is world's second producer of coffee (Anonymous, 2006). To consolide its economic success and sustainability, a technological model of production is crucial to improve its quality (Paulo et al., 2010). 
Such as several agricultural products, coffee presents high moisture content when harvested. Losses caused by excessive moisture and high sugar content in the coffee pulp may be intensified if postharvest techniques are not applied in the most efficient manner (Quintero, 1999).

The behavior of coffee beans is similar to different agricultural products, which are capable of relish or absorb water from the surrounding, known as hygroscopicity. To guarantee the high final quality of the product, it is important to store coffee in dry places with low moisture content. The contrary would increase the incidence of microorganisms that cause undesirable fermentations and toxin contamination, depreciating the product's quality and commercialisation (Yazdani et al., 2006).

To avoid losses after harvest and therefore economic, coffee must undergo technological transformations such as drying and powdering. These technological transformations will extend its shelf life while ensuring the stability of its quality.

Coffee beans undergoes postharvest physiological deterioration needed postharvest handling to keep the quality, as make it into powder (instant) coffee. Instantiation of any food product will affect the equilibrium moisture content which changes the nature of itself (Moreno et al., 2003).

To correctly conduct drying, grinding and storage operations, it is necessary to know the realationship between air temperature and relative humidity, and desirable conditions for preserving the product. To obtain this information, sorption isotherms are indispensable. Sorption isotherms describe the relationship between the equilibrium moisture content and the water activity at constant temperatures. They give information about the water sorption mechanism and interactions between food components and water. They are also extremely important in modelling of the drying process, in design and optimisation of drying equipment, in predicting shelf-life stability, in determining critical moisture, in selecting appropriate packaging material and water activity for acceptability of products that deteriorate mainly by moisture gain (Kaymak-Ertekin and Gedik, 2004).

It is common to present sorption isotherms by mathematical models based on empirical and / or theoretical criteria. In the literature there is a long list of available isotherm models, which can be divided into several categories; kinetic models based on an absorbed mono-layer of water (BET model) (Brunauer-Emmett-Teller : Brunauer et al., 1938), kinetic models based on a multi-layer and condensed film (e.g. Halsey model, Van den Berg and Bruin, 1981), semi-empirical (e.g. Halsey model, Halsey, 1948) and purely empirical models (e.g. Oswin and Smith models, Oswin, 1946 ; Smith, 1947).

In view of the importance of understanding the hygroscopicity of agricultural products, this work aimed to determine and model the sorption isotherms of coffee powder and to fit several mathematical models to the experimental data.

\section{Materials and methods}

\section{Biological material}

The coffee (Arabusta) used in this study was grown on the experimental plots of the agronomic research center of Divo (Côte d'Ivoire). This study was conducted at the laboratory of this center in Bingerville (Côte d'Ivoire). Coffee was harvested manually during the cherry stage. During harvest, unripened, deteriorated and damaged coffee beans were removed. Due to the high initial moisture content and the risks associated with this tendency (development of the micro-organism, plague attack), the coffee was dried on the trays. The dried coffee was roasted and put into powder form. The coffee powder will be used to determine the adsorption isotherms.

\section{Experimental procedure}

The methodology used to obtain the equilibrium 
data was based on the dynamic method with satured salt solutions. The salts were chosen, to obtain a large range of water activity. The equilibrium moisture contents of coffee were determined by a gravimetric technique, in which the weigh changes were monitored continuously within a dynamic system of thermally stabilized. Although this method requires a long time for the hygroscopic equilibrium to be obtained, it has the avantage of presenting a more restricted domain of moisture content variation (Jamali et al., 2006).

Six different salts viz., $\mathrm{KOH}, \mathrm{LiCl}, \mathrm{MgCl}_{2}, \mathrm{NaCl}$, $\mathrm{KCl}$ and $\mathrm{K}_{2} \mathrm{SO}_{4}$, and were used to maintain respective water activity (aw) inside separate vacuum desiccators in range of 0.07 to 0.97 . Table 1 shows the standard value of water activities given for the six salts.

Table 1. Water activity values of the saturated salt solution at laboratory temperature.

\begin{tabular}{ll}
\hline Saturated salt solutions & Temperature $\left(\mathbf{2 9}^{\circ} \mathbf{C}\right)$ \\
\hline $\mathrm{KOH}$ & 0.077 \\
$\mathrm{LiCl}$ & 0.11 \\
$\mathrm{MgCl} 2$ & 0.32 \\
$\mathrm{NaCl}$ & 0.73 \\
$\mathrm{KCl}$ & 0.88 \\
$\mathrm{~K}_{2} \mathrm{SO}_{4}$ & 0.97 \\
\hline
\end{tabular}

The equilibrium moisture content of coffee powder was determined by a gravimetric technique at six relative humidities selective between $7 \%$ and $97 \%$ at $29^{\circ} \mathrm{C}$. Sulphuric acid solutions were used to maintain the specified relative humidity inside the desiccators (Ruegg, 1980). Coffee powder samples $(2 \pm 0.001 \mathrm{~g})$ were placed in previously weighed aluminium dishes and dried at $45^{\circ} \mathrm{C}$ in an aircirculated oven over silica gel for 3 days. The samples were subsequently kept in desiccators over sulphuric acid solutions of known relative humidity.

A test tube containing thymol was placed inside the desiccators with high relative humidity to prevent mold growth during storage. The desiccators were placed in the laboratory at room temperature and the samples were allowed to equilibrate until there was no discernible weight change $( \pm 0.001 \mathrm{~g})$. This involved a period of approximately three weeks. The total time for removal, weighing and putting back the samples in the desiccators was about $30 \mathrm{~s}$. This minimized the degree of atmospheric moisture sorption during weighing.

The equilibrium moisture content was determined by drying in an over at $70^{\circ} \mathrm{C}$ until constant weight. All measurements were done in triplicate.

\section{Modelling equations}

The isotherm models used to fit the data are presented in Table 2. The experimental adsorption data of all samples was fitted to seven sorption equation. These equations were chosen because they are most widely used to fit experimental sorption data of various food materials. The parameters of the sorption models were estimated from the experimental results using the nonlinear regression analysis (SPSS 9.0 for Windows 1998) which minimises the residual sum of squares.

The constants were estimated by fitting the mathematical model to the experimental data, using a non-linear regression analysis with Microsoft Excel 2007 software. The quality of the fitting of different models was evaluated by calculating the correlation coefficient $\left(\mathrm{R}^{2}\right)$ and the mean relative percentage deviation modulus (MRD \%) between the experimental and predicted equilibrium moisture content (Boquet et al., 1978; Basu et al., 2006).

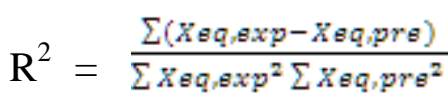

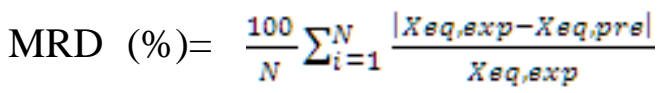

Where $\mathrm{N}$ is the number of observations, Xeq, exp and Xeq, pre are the experimental and predicted values of the equilibrium moisture content, respectively.

The mean realtive percentage deviation modulus is widely adopted throughout the literature, with a 
modulus value below 10\% indicative of a good fit for pratical purpose (Lomauro et al., 1985). In the same way, the smaller the MRD (\%) value, the better the fit of the model.

In the GAB model, $\mathrm{Xm}$ is the moisture content corresponding to the formation of a monomolecular layer on the internal surface; $G$ is a constant related to the heat of sorption of the first layer on primary sites and $\mathrm{K}$ is a factor correcting properties of the multi-layer molecules with respect to the bulk liquid.

Table 2. Isotherm equations for experimental data fitting.

\begin{tabular}{|c|c|c|}
\hline Model & Mathematical expression & aw range \\
\hline BET (Brunauer et al., 1938) & $\mathrm{Xeq}={ }^{X m C a w} /[(1-a w)(1+(C-1) a w)]$ & (1) $a w<0.50$ \\
\hline $\begin{array}{l}\text { GAB (Van den Ben and Bruin, } \\
\text { 1981) }\end{array}$ & $\mathrm{Xeq}={ }^{X m C K a w} /[(1-K a w)(1+$ CGKaw - Kaw $)]$ & (2) $0.05<a w<0.95$ \\
\hline Chung and Pfost (1967) & $\mathrm{Xeq}=\frac{1}{B}[\ln A-\ln (-\ln a w)]$ & (3) $0.20<a w<0.90$ \\
\hline Hasley (1948) & $\mathrm{Xeq}=(-A / \text { naw })^{\frac{1}{B}}$ & (4) $0.05<a w<0.80$ \\
\hline Kuhn (Labuza et al., 1972) & $\mathrm{Xeq}=A /$ lnaw $+B$ & (5) $a w<0.5$ \\
\hline Oswin (1946) & $\mathrm{Xeq}={ }_{\mathrm{A}}[a w /(1-a w)]^{B}$ & (6) $0.05<a w<0.90$ \\
\hline Freundlich (1906) & $\mathrm{Xeq}=\mathrm{A}(\alpha w)^{\frac{1}{B}}$ & (7) $a w<0.90$ \\
\hline
\end{tabular}

\section{Results and discussion}

\section{Equilibrium moisture content}

Coffee powder is a hygroscopic food product that could adsorp the water vapor from the environment to its material. The adsorption happened during the study from the satured salt solution into product to the state of constant. It has been known the minimum of instant coffee moisture content using BET and GAB models to keep its stability, so it is able to be the basic directors to select appropriate materials. The experimental data showed that the moisture adsorption followed type II behavior (Labuza, 1984). The relation between instant coffee equilibrium moisture content and the water activity can be seen at Fig. 1 .

The moisture content of coffee powder increased by the increasing of water activity at the storage condition. Based on the experimental data, Xeq, exp value at the lowest $a w$ of 0.07 was $23.7 \mathrm{~g}$ water per $100 \mathrm{~g}$ dry matter and at the highest $a w$ of 0.97 was $77.9 \mathrm{~g}$ water per $100 \mathrm{~g}$ dry matter.

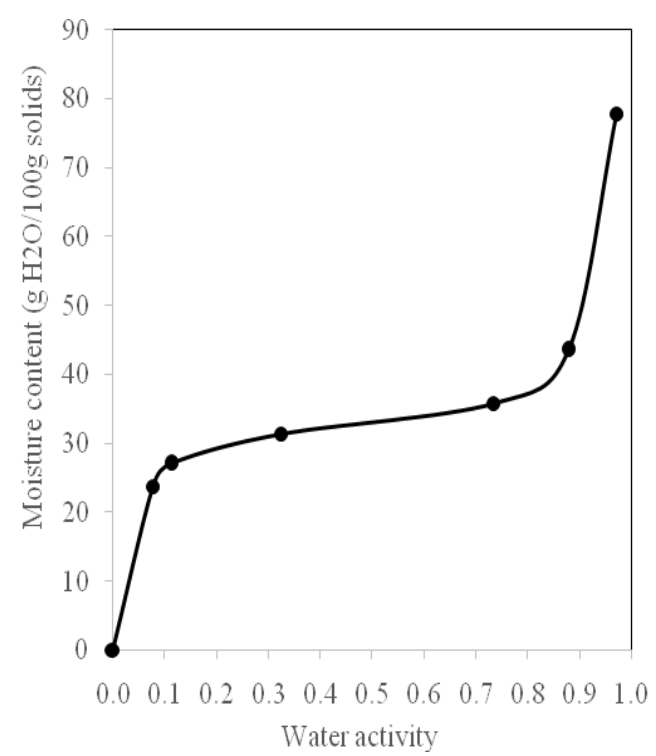

Fig. 1: Adsorption isotherms of coffee (Arabusta) powder at $29^{\circ} \mathrm{C}$. 
The sigmoid shapes of the moisture adsorption isotherms, which are typical of food istherms, can be observed. The curve pattern of coffee powder during storage followed the sigmoid type II behavior, which demonstrated its capability in adsorb a water vapor (Labuza, 1984). In the first segment (with low $a w$ ) of the S-shaped sorption isotherm curves, coffee powder adsorbed relatively lower amounts of moisture per unit increase in water activity. However, larger amount of moisture was adsorbed at higher $a w$.

This is a type of dried food product, namely sigmoid shape. The pattern sigmoid formed due to stock exchange colligative, capillaries and interaction between the surfaces (Labuza, 1984). The sigmoid type II behavior was reported from several research that also contained starch, such as dried cassava flour, cassava rice, cassava flour, instant corn flour and grain cereal (Wijaya et al., 2016). In this type, there are 2 arches that demonstrate its existence of physic-chemical changes of coffee powder's water binding. First one, which is at $a w$ of 0.07 and the second one is at $a w$ of 0.73 . Similar behaviour has been reported by other authors for different food (Torgul and Arslan, 2007). This phenomenon occurs in food rich in sugars (Simal et al., 2007).

\section{The fitting of various models to moisture sorption isotherm of coffee powder}

The experimental moisture sorption data produced curve that less than perfect, thus the data were fitted to seven models to get a smooth curve (Fig. 2). Seven models that were used in this reseach, namely BET, Oswin, Kuhn, Hasley, Chung and Pfost, Freundlich and GAB models. The models were chosen due to their suitability to describing the moisture sorption curve in large range of aw (Isse et al., 1993).

These mathematical equations are converted to linear form to determine coefficient of drag coefficient that is needed in order to make it easier for the count. The equation of each model are presented in Table 2.
Guggenheim-Anderson-de Boer model has been used based on its theoretical background, which reflects the adsorption pattern in the range of large $a w$ from $a w$ of 0 to $a w$ of 0.90 . This model is a model that suitable to be used in food product of fruits, meats and vegetables.

In most models, the constant values are only numbers in a product characteristic and cannot be explained by theoretical backgrounds, but the BET and GAB models produces constant values which can be explained. As well as the BET model, the GAB model also been used to calculate the monolayer moisture content. The monolayer moisture content $(\mathrm{Xm})$ of coffee powder have been predicted by using BET and GAB model, which were $22.15 \mathrm{~g}$ water per $100 \mathrm{~g}$ dry matter and $2.57 \mathrm{~g}$ water per $100 \mathrm{~g}$ dry matter, respectively. This amount of moisture content has significance effect in storage and product distribution, where this is the minimum amount of water that are bound to not be able to be used for the growth of microorganism, chemical reaction, and biological reactions to make the longer shelf life (Wijaya et al., 2016). The more fat content in a product, the more decrease the number of water that can be bound by a food in the upper layers monolayer.

The monolayer moisture content prediction of BET model is higher than the GAB model. It might be caused the BET model consider there is a multilayer on the monlayer one. This is similar to a study by Wariyah and Supriyadi (2010) in rich calcium rice that has moisture content of 0.0721-0.0867 $\mathrm{g} \mathrm{H}_{2} \mathrm{O} / \mathrm{g}$ solid, and also by LiendoCardenas et al. (2000) in cereal products cassava with moisture content of 0.061-0.097 $\mathrm{g} \mathrm{H}_{2} \mathrm{O} / \mathrm{g}$ solid in four different temperatures.

In a study by Houssein (2007) in pasta dates was getting moisture content of $0.084 \mathrm{~g} \mathrm{H}_{2} \mathrm{O} / \mathrm{g}$ solid using a model GAB. The value of the monolayer moisture content $(\mathrm{Xm})$, indicates the amount of water that is strongly adsorbed to specific sites at the food surface, and this is a value that must be reached in order to assure its stability. 


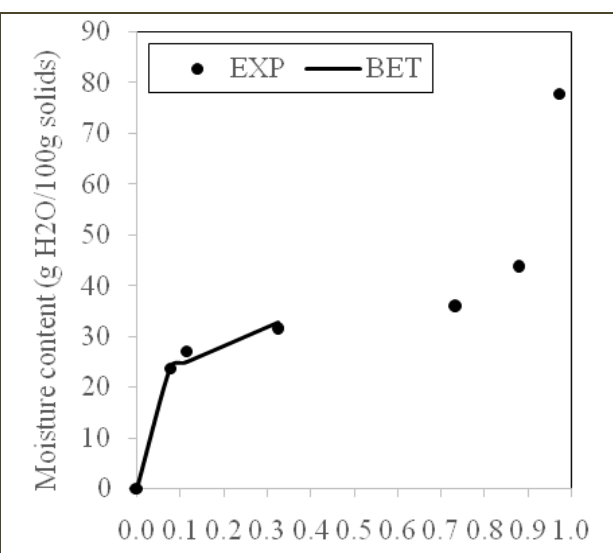

Water activity

(a)

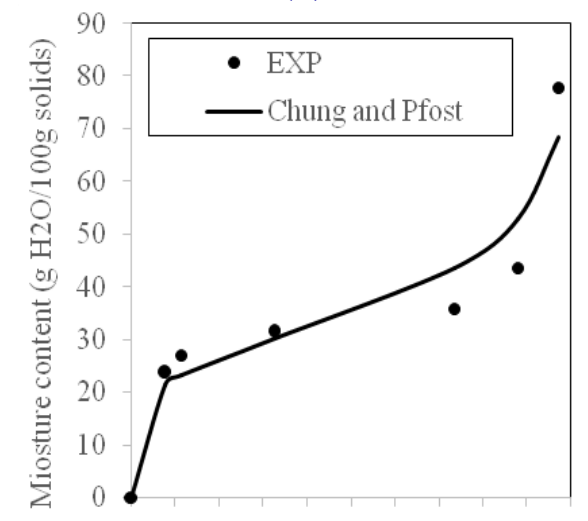

0.00 .10 .20 .30 .40 .50 .60 .70 .80 .91 .0

Water activity

(d)

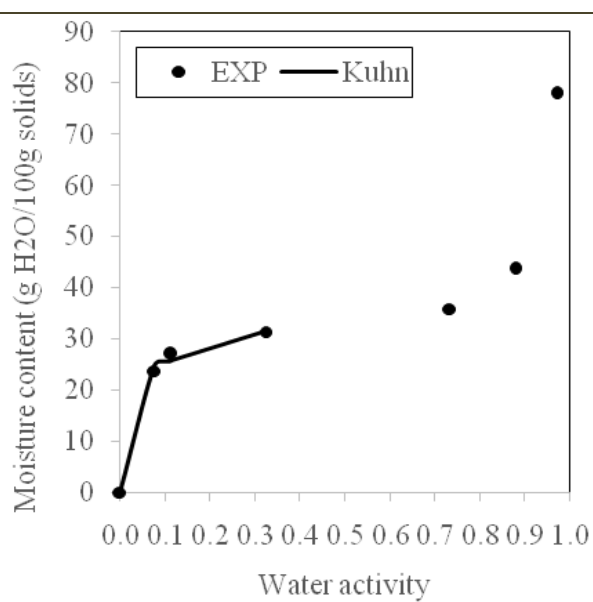

(b)

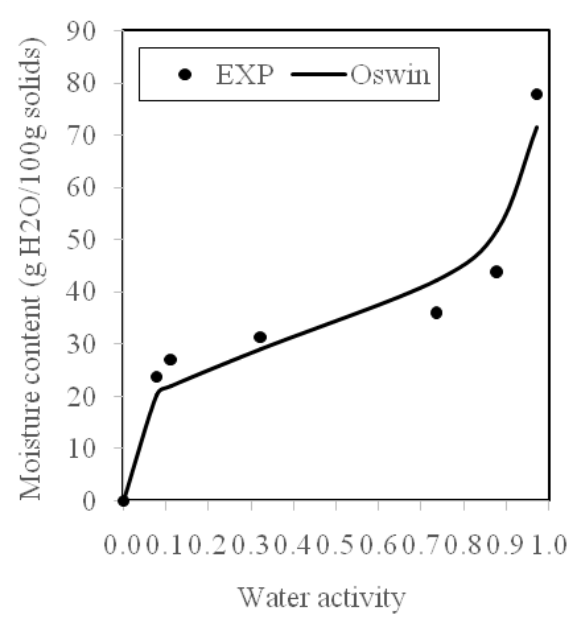

(e)

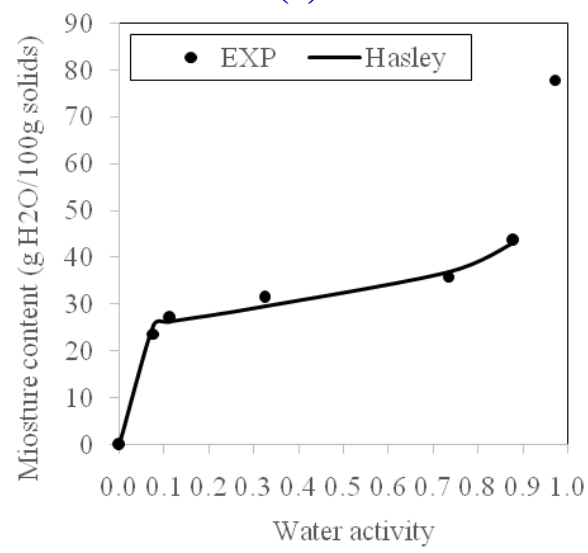

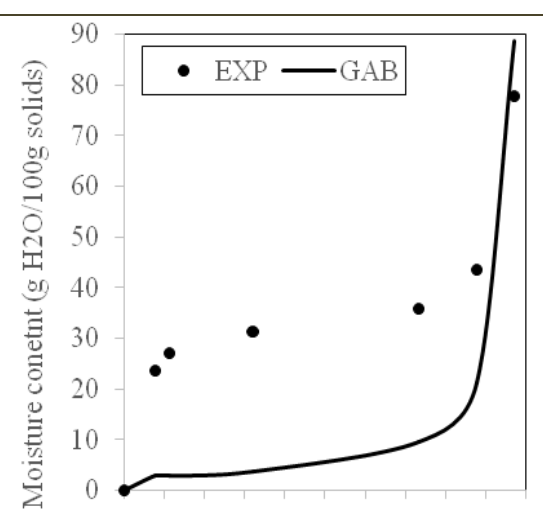

0.00 .10 .20 .30 .40 .50 .60 .70 .80 .91 .0

Water activity

(c)

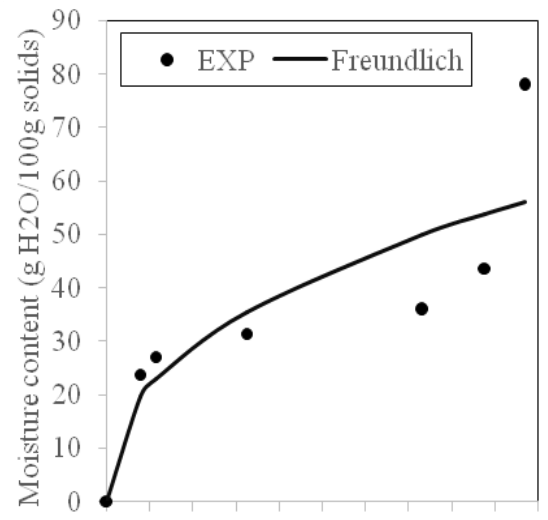

0.00 .10 .20 .30 .40 .50 .60 .70 .80 .91 .0

Water actiity

(f)

(g)

Fig. 2: Sorption isotherms of coffee powder predicted by : (a) Brunauer-Emmet-Teller (BET) model, (b) Kuhn model, (c) Guggenheim-Anderson-de Boer (GAB) model, (d) Chung Pfost model, (e) Oswin model, (f) Freundlich model and (g) Hasley model.

The coefficients of the GAB, BET, Kuhn, Hasley, Oswin, Chung and Pfost and Freundlich, their mean relative deviation (MRD\%) and co-efficient of determination $\left(\mathrm{R}^{2}\right)$ were used to analyze the fitness of model (Table 2). The suitability of these seven models were evaluated statically by using Mean Relative 
Determination (MRD) method with the value of $<5$ describes that the model was precise, $<10$ describes the model was almost precise and $>10$ describes the model was imprecise. Lower the values of MRD, better is the goodness of fit of the model. The counted result of MRD (\%) can be seen in the Table 3.

Table 3. Estimated values of constants, correlation coefficient ( $r$ ) and the mean relative percentage deviation modulus (MRD) obtained for the models.

\begin{tabular}{|c|c|c|}
\hline Model & Constants & Values \\
\hline \multirow[t]{5}{*}{ GAB } & $\mathrm{Xm}$ & 2.5731853 \\
\hline & $\mathrm{C}$ & 507342.82 \\
\hline & $\mathrm{K}$ & 507342.82 \\
\hline & $\mathrm{R}$ & 0.9848813 \\
\hline & $\operatorname{MRD}(\%)$ & 0.6724809 \\
\hline \multirow[t]{4}{*}{ BET } & $\mathrm{Xm}$ & 22.147181 \\
\hline & $\mathrm{C}$ & 100498.52 \\
\hline & $\mathrm{R}$ & 0.9406221 \\
\hline & MRD (\%) & 0.0442276 \\
\hline \multirow[t]{4}{*}{ Kuhn } & A & -13.58112 \\
\hline & B & 19.517881 \\
\hline & $\mathrm{R}$ & 0.9491528 \\
\hline & $\operatorname{MRD}(\%)$ & 0.0335177 \\
\hline \multirow[t]{4}{*}{ Hasley } & A & 239512469 \\
\hline & $\mathrm{B}$ & 5.6662956 \\
\hline & $\mathrm{R}$ & 0.980833 \\
\hline & $\operatorname{MRD}(\%)$ & 0.0418995 \\
\hline \multirow[t]{4}{*}{ Oswin } & $\mathrm{A}$ & 34.049842 \\
\hline & B & 0.2118331 \\
\hline & $\mathrm{R}$ & 0.9518924 \\
\hline & $\operatorname{MRD}(\%)$ & 0.1428906 \\
\hline \multirow[t]{4}{*}{ Chung and Pfost } & $\mathrm{A}$ & 19.611891 \\
\hline & B & 0.095075 \\
\hline & $\mathrm{R}$ & 0.9318073 \\
\hline & $\operatorname{MRD}(\%)$ & 0.1398012 \\
\hline \multirow[t]{4}{*}{ Freundlich } & $\mathrm{A}$ & 56.784931 \\
\hline & $\mathrm{B}$ & 2.3991299 \\
\hline & $\mathrm{R}$ & 0.7624317 \\
\hline & $\operatorname{MRD}(\%)$ & 0.2283677 \\
\hline
\end{tabular}

Based on statistical parameters and ease of use, three models (BET, Khun and Hasley) presented a good fit to the experimental data. However, it is clear from this Table 3 that Hasley model is a model that quite accurately describes characteristics of coffee powder, with the value of MRD (4\%) less than $10 \%$ and coefficient of determination $\left(\mathrm{R}^{2}\right)$ is 0.98 from polynomial regression. There is a good agreement with the results of Ayranci et al. (1990), Yanniotis et al. (1990) for grapes and McLaughlin and Magee (1998) for potatoes. Kaymak-Ertekin and Sultanoglu (2001) concluded that the Hasley equation gave the best fit for peppers.

Although BET and Kuhn model produced MRD (\%) value of $4 \%$ and $3 \%$, respectivily; their compatibility are only able to predict with good only until aw 0.5 . Thus Kuhn model is better than BET model on this water activity range.

The Chung and Pfost, Oswin, Freundlich and GAB models did not satisfactorily describe the behavior 
of the coffee powder adsorption isotherms with the MRD (\%) values of $13 \%, 14 \%, 22 \%$ and $67 \%$, respectivily. This statement is contrary to a number of studies have shown that these models have been successful in providing reasonable fit to sorption isotherms of several foods (Wang and Brennan, 1991; Peng et al., 2007; Moussa et al., 2014; Erhayem et al., 2015).

The GAB was the poorest model in simulating the adsorption data of coffee powder obtaining overall MRD value of $67 \%$. Previous studies have shown that GAB model is unsuitable for describing the water sorption relations of starchy materials. This result confirms the work of Zapata et al. (2014) on the sorption isotherms for oat flakes (Avena sativa L.). This result does not agree with Brett et al. (2009), who reported a good fit with GAB and BET models to oat flour (Brett et al., 2009), nor with Ayala (2011), who reported good fit in cassava flour with the GAB, Oswin and Smith models, or with Gálvez et al. (2006), who observed good fit in cornflour with the GAB and Oswin models.

\section{Conclusion}

In this study, the adsorption isotherms of coffee powder was determined under laboratory conditions $\left(29^{\circ} \mathrm{C}\right)$ over the water activity range of 0.07 to 0.97 , using the static gravimetric method. Experimental results illustrated that equilibrium moisture content (EMC) increased as water activity increased. The moisture adsorption isotherms of coffee powder follows a sigmoid isotherm curve typical of the type II classification shape. Moisture sorption characteristics of coffee powder could be predicted agreeably with BET, Kuhnand Halsey model. However, Halsey model was found to be more suitable for accurate prediction of sorption isotherm with ar elative deviation percent below 10\%. The model developed in the present study may be utilized in predicting the equilibrium moisture content of coffee powder at $29^{\circ} \mathrm{C}$ and relative humidity. This study will help in designing packaging systems of a nutritious product like coffee so that it can be stored for a longer period for preparations of value added products.

\section{Conflict of interest statement}

Authors declare that they have no conflict of interest.

\section{References}

Anonymous, 2006. Elaboration d'un plan national qualité café cacao : Etude diagnostique. Rapport final, Bourse du café et du cacao (BCC) (p.60), Abidjan.

Ayala, A., 2011. Estimación de las isotermas de adsorción y del calor isostérico en harina de yuca. Biotecnol. Sector Agropec. Agroind. 9(1), 88-96.

Ayranci, E., Ayranci, G., Dogantan Z., 1990. Moisture sorption isotherms of dried apricot, fig and raisin at $20^{\circ} \mathrm{C}$ and $30^{\circ} \mathrm{C}$. J. Food Sci. 55, 1591-1593.

Basu, S., Shivhare, U. S., Mujumdar, A. S., 2006. Model for sorption isotherms for food: A review. Drying Technol. 24, 917-930.

Boquet, R., Chirife, J., Iglesias, H. A., 1978. Equations for fitting water sorption isotherms of foods. II. Evaluation of variuos two-parameter models. J. Food Technol. 13, 319-327.

Brett, B., Figueroa, M., Sandoval, A. J., Barreiro, J., A., 2009. Moisture sorption characteristics of starchy products : oat flour and rice flour. Food Biophys. 4, 151-157.

Brunauer, S., Emmett, P. H., Teller, E., 1938. Adsorption of gases in multimolecular layer. $\mathrm{J}$. Am. Chem. Soc. 60(2), 309-319.

Chung, D. S., Pfost, H. B., 1967. Adsorption and desorption of water vapor by cereal grains and their products. Part II: Development of the general isotherm equation. Trans. ASAE. 10, 552-555.

Erhayem, M., Al-Tohami, F., Mohamed, R. Ahmida, K., 2015. Isotherm, kinetic and thermodynamic studies for the sorption of mercury (II) onto activated carbon from Rosmarinus officinalis leaves. Am. J. Anal. Chem. 6, 1-10.

Freundlich, H., 1906. Adsorption in solutions. J. Phys. Chem. 57, 384-410.

Gálvez, V., Aravena, L., Mondaca, L., 2006. 
Isotermas de adsor-ción en harina de maíz. Ciênc. Tecnol. Aliment. 26, 821-823.

Hasley, G., 1948. Physical adsorption in nonuniform surfaces. J. Chem. Phys. 16, 931-945.

Houssein, T. A., 2007. Water sorption isotherms of Libyan date paste. M. Sc. Thesis. The Middle East Technical University, Turkey. 66p.

Isse, M. G., Schuchmann, H., Shubert, H., 1993. Divided sorption isotherm concept: an alternative way to describe sorption isotherm data. J. Food Process Eng. 16 (2), 147-157.

Jamali, A., Kouhila, M., Ait Mohamed, L., Idliman, A., Lamharrar, A., 2006. Moisture adsorptiondesorption isotherms of Citrus reticulata leaves at three temperatures. J. Food Eng. 77(1), 7178.

Kaymak-Ertekin, F., Gedik, A., 2004. Sorption isotherms and isosteric heat of sorption for grapes, apricots, apples and potatoes. Lebensm.Wiss. Technol. 37, 429-438.

Kaymak-Ertekin, F., Sultanoglu, M., 2001. Moisture sorption isotherm characteristics of peppers. J Food Eng. 47, 225-231.

Labuza T. P., McNally L., Gallagher D., Hawkes J. and Hurtado F. 1972. Stability of intermediate moisture foods. 1. Lipid oxidation. J. Food Sci. 37(1), 154-159.

Labuza, T. P., 1984. Moisture sorption : practical aspects of isotherm measurement and use. St. Paul, Minnesota: American Association of Cereal Chemists.

Liendo-Cardenas, M., Zapata-Norena, C. P., Brandelli, A., 2000. Sorption isotherm equations of potato flakes and sweet potato flakes. Braz. J. Food Technol. 3, 53-57.

Lomauro, C. J., Bakshi, A. S., Labuza, T. P., 1985. Evaluation of food moisture sorption isotherms equations. Part I. Fruit vegetable and meat products. Lebensm.-Wiss. Technol.18, 111117.

McLaughlin, C. P., Magee, T. R. A., 1998. The determination of sorption isotherm and the isosteric heats of sorption for potatoes. J Food Eng. 35, 267-280.

Moreno, R. C., Carilo, J. M., Dorado, R. G., Lopez, O. P., Rodriguez, E. O. C., Tiznado J. A. G., 2003. Instant Flour From Quality Protein aise
(Zea mays L.): Optimisation of Extrusion process. LWT- Food Sci. Technol. 5, 01-06.

Moussa, W., Mohamad, F., Ghazali, Jinap, S., Mohd, H., Ghazali, Radu, S., 2014. Sorption isotherms and isosteric heats of sorption of Malaysian paddy. J. Food Sci. Technol. 51 (10), 2656-2663.

Oswin, C. R., 1946. The kinetics of package life. III- The isotherm. J. Chem. Ind. 65, 419-421.

Paulo, C. C., André, L. D. G., Paulo, C. A. J., Gabriel, H. H. O., Domingos, S. M. V., 2010. Moisture sorption isotherms and isosteric heat of sorption of coffee in different procesing levels. Int. J. Food Sci. Technol. 45, 2016-2022.

Peng, G., Chen, X., Wu, W., Jiang, X., 2007. Modelling of water sorption isotherm for corn starch. J Food Eng. 80, 562-567.

Quintero, G. I. P., 1999. Influencia del proceso de beneficio en la calidad del cafe. Cenicafé. 50, 78-88.

Ruegg, M., 1980. Calculation of the activity of water in sulphuric acid solutions at various temperature. Lebensm.-Wiss. Technol. 13, 2224.

Simal, S., Femenia, A., Castell-Palou, A., Rossello, C., 2007. Water desorption thermodynamic properties of pineaple. J. Food Eng. 80, 12931301.

Smith, S. E., 1947. The sorption of water vapour by high polymers. J. Am. Chem. Soc. 69, 646-651.

Torgul, H., Arslan, N., 2007. Moisture sorption isotherms and thermodynamic properties of walnut kermels. J. Stored Prod. Res. 45, 252264.

Van den Berg, C., Bruin, S., 1981. Water activity and estimation in food systems: theoretical aspect. In: Water Activity: Influences on Food Quality (Eds.: Rockland, L.B., Stewart, G.F.). Academic, New York. pp.147-177.

Wang, N., Brennan, J. G., 1991. Moisture sorption isotherm characteristics of potato at four temperatures. J Food Eng. 14, 269-287.

Wariyah, C., Supriyadi, 2010. Moisture sorption isotherm of calcium fortified rice. Agritech. 30 (4), 199-203.

Wijaya, I. M. A. S., Fitriani, P. P. E., Gunam, I. B. W., Wrasiati, L. P., 2016. Moisture sorption 
isotherm characteristics of instant cassava (Manihot esculenta Crantz) at various fitting models. International Conference on Agriculture and Food Engineering (CAFEI 2016), 23-25 August 2016.

Yanniotis, S., Nikoletopoulos, P., Puppas, G., 1990. Sorption models for dried fruits. In: Engineering and Food. Physical Properties and Process Control (Eds.: Spiess, W. E. L.,
Schubert, H.). Vol. I. Elsevier Applied Science, London. pp.547-582.

Yazdani, M., Sazandehchi, P., Azizi, M., Ghobadi, P., 2006. Moisture sorption isotherms and isosteric heat for pistachio. Eur. Food Res. Technol. 223, 577-584.

Zapata, J. E. M., Quintero, O.A. C., Porras, L. D. B, 2014. Sorption isotherms for oat flakes (Avena sativa L.) Agron. Colomb. 32(1), 52-58.

\section{How to cite this article:}

Yué Bi, C. Y., Yao, B. N., Konan, R. B., Akmel, C. D., Tano, K., 2018. Moisture adsorption isotherms characteristic of coffee (Arabusta) powder at various fitting models. Int. J. Curr. Res. Biosci. Plant Biol. 5(2), 26-35. doi: https://doi.org/10.20546/ijcrbp.2018.502.004 